\title{
Mobile Teaching of Digital Mapping Based on the WeChat Official Account Admin Platform
}

\author{
https://doi.org/10.3991/ijet.v12i07.7225 \\ Caiyun Gao \\ Henan University of Urban Construction, Pingdingshan, China \\ gaocaiyungao@ 163 .com \\ Jingyan Wang \\ Shijiazhuang Information Engineering Vocational Collage, Shijiazhuang, China \\ 44495564 @qq. com
}

\begin{abstract}
Digital mapping is a core and basic course for students who are majoring in Surveying and Mapping Engineering. The traditional teaching model, which is limited by classroom size, credit hours, and many other factors, can barely meet the teaching demands of a modern classroom. The continuous optimization of mobile techniques and the mobile environment has been witnessed in recent years. Several mobile terminals have emerged, which strongly support the future of micro-learning of digital mapping. This study builds a mobile digital mapping teaching system to explore effective learning models for mobile terminals. Content analysis is combined with questionnaire survey to analyze the basic characteristics of learners, learning content, learning behavior, and learning effects. Results suggest that the WeChat official account admin platform plays a positive role in attracting learners, spreading micro-content, promoting personalized learning, and evaluating real-time learning effects. In summary, this study enriches research on mobile teaching and provides teachers with new perspectives in teaching digital mapping and other specialized courses to Surveying and Mapping Engineering majors.
\end{abstract}

Keywords-WeChat official account admin platform; digital mapping; mobile learning

\section{Introduction}

Digital mapping is an important course that plays a fundamental role, not only in teaching activities to students majoring in Surveying and Mapping Engineering, but also in enriching their learning and research skills [1-2]. Most universities and colleges in China combine indoor theoretical teaching and outdoor practices as the teaching model for digital mapping. However, this teaching model presents the following problems: (1) serious lack of communication between the teacher and the students because of limited classroom size and credit hours, (2) deviations in the understanding of knowledge points due to the different learning abilities of students, and (3) lack of diversified classroom teaching models that meet the demands of modern classroom 
teaching. These issues make reforming the digital mapping teaching model via modern information technology (IT) an imperative[3-4].

The development of the Internet and IT has enabled people to use mobile phones, tablet PCs, and many other mobile devices to acquire information, resources, and services at any time and place, thereby paving the way for a new type of learning, i.e., mobile learning. At present, mobile learning models can be classified into mobile learning based on (1) online browsing, (2) multimedia communication (e.g., email), (3) mobile learning software, (4) Short Message Service, and (5) real-time interaction software. The first four models exhibit poor performance in instantaneous interaction, have single interaction forms, and have high interaction cost. By contrast, the last model exhibits overwhelming advantages that include strong interaction functions, low interaction cost, easy operation, and wide applications. Therefore, mobile learning based on real-time interaction software may be an ideal choice for mobile teaching. However, the final interaction effects of this learning model remain dependent, to a considerable extent, on which interaction software is adopted. In China, instant messaging software services, such as QQ, Weibo (China's version of Twitter), and WeChat, have a large number of mobile users. Among these services, WeChat provides the strongest mobile learning functions and is extremely popular among college students. Hence, the present study aims to build an interactive mobile teaching model based on WeChat to assist in teaching digital mapping.

\section{State of Art}

WeChat is a mobile application launched by Tencent in 2011 that provides free instant messaging services. Users can send voice messages, video clips, photos, and text messages to an individual (one-to-one) or a group of individuals (one-to-many) over the Internet; this interaction function is powerful . Official statistics from WeChat indicated that WeChat covered over $94 \%$ of smartphone users in China by the second quarter of 2016. Among them, 806 were monthly active users and $84.7 \%$ were college students. College students use WeChat as their main communication tool, and thus, it also provides a new channel for mobile teaching [5-6].

With the popularity of WeChat, mobile teaching based on the WeChat official account admin platform has gradually received research interest among scholars, both local and abroad. Research attention mainly focuses on (1) a mixed teaching design and learning evaluation and (2) a case study of course teaching using the WeChat official account admin platform. For example, Wang studied the learning support function of WeChat and explored the design principles of mobile learning based on WeChat [7]. Liu presented design principles and flow for the WeChat-based mobile learning platform and built one of her own [8]. Xie launched shared courses on the WeChat official account admin platform [9]. The works of the aforementioned scholars covered the functions, characteristics, and advantages of the WeChat official account admin platform; the application status and prospects of WeChat in the field of education; and a case study of course teaching using WeChat. However, research on the applications of the WeChat official account admin platform to teaching practices 
remains in its initial stage in China. In particular, the applications of this platform to surveying courses are insufficiently studied. The present study is conducted to fill in the aforementioned research gap. A mobile digital mapping teaching system based on the WeChat official admin platform is built. This system consists of a pre-class module, a classroom module, and a post-class module. Subsequently, content analysis combined with questionnaire survey is performed to study the basic characteristics of learners, learning content, learning behavior, and learning effects.

\section{Building of Digital Mapping Teaching Model Based on the Wechat Official Account Admin Platform}

The digital mapping teaching model based on the WeChat official account admin platform should include the core elements, namely, a preliminary survey, a teaching system design, and executive control of WeChat teaching [10].

\subsection{Preliminary survey}

The preliminary survey is composed of a feasibility analysis of the use of WeChat as an aid for teaching digital mapping and the confirmation of the WeChat teaching topic.

Feasibility analysis: In 2014, Henan University of Urban Construction basically completed campus informatization and digitalization with a wireless network that covered the teaching buildings, office buildings, library, squares, canteens, and the apartments of the students. Through this development, students can connect their mobile devices to the Internet at any time and place within the campus.

Survey of the basic situations of students: To explore the potential of WeChatbased mobile learning, the author conducted a questionnaire survey among 166 students majoring in Surveying Engineering and Geographical Information System who were admitted to Henan University of Urban Construction in 2014. The questionnaire survey aimed to determine whether students have a smartphone, a tablet PC, or other smart mobile devices, as well as the attitude of the students toward WeChat and WeChat-based teaching. The results show that $96 \%$ of the respondents have a smartphone and a WeChat account; $89 \%$ are familiar with the basic functions of WeChat, including chatting, forming a WeChat group, updating moments, and sending video messages; $95 \%$ are curious about WeChat-aided teaching of digital mapping and support its implementation; whereas 5\% are neutral about the subject.

Survey of WeChat teaching topics: To guarantee the smooth implementation of WeChat-based digital mapping mobile teaching, the author investigates knowledge points that students are required to grasp, that students are interested in, and that are difficult to understand based on the requirements of the digital mapping teaching syllabus. The survey results show that $92 \%$ of the respondents are interested in picket point surveying, electronic plane table surveying, the construction of digital elevation models, and the automatic generation of contour lines. They hope that they can acquire such knowledge through an interactive and autonomous learning model. Fur- 
thermore, $89 \%$ of the students are eager to learn frontier techniques beyond textbooks, $87 \%$ prefer to interact with teachers on the WeChat official account admin platform to discuss key knowledge points, and 100\% hope that the course can include large-scale digital surveying engineering cases.

\subsection{WeChat Design and realization of the digital mapping teaching system}

Design of course resources: Henan University of Urban Construction offers digital mapping lessons based on the Digital Mapping Principles and Methods, a textbook designated by the Higher Education Guidance Committee of the China Society for Geodesy, Photogrammetry, and Cartography. The content of the textbook does not only meet the basic requirements of "Surveying Engineering Professional Standards" on talent training, but also fully reflect new developments, techniques, and requirements of surveying subjects as highly practical, applicable, and foremost. Through this textbook, students can grasp theoretical knowledge and new techniques in surveying engineering. Moreover, they can become familiar with operating different surveying instruments to finish field measurement tasks quickly, adeptly, and independently.

The author is able to identify the learning demands of students through the results of the preliminary survey. Accordingly, a WeChat group is built based on these learning demands, and specific knowledge points in the textbook are posted on the WeChat official account admin platform.

Design and implementation of the digital mapping teaching platform based on the WeChat official accounting platform: The development of the WeChat teaching platform is student-oriented and teacher-dominated. The platform aims to enable full play of student learning autonomy and to develop effective interaction among teachers, students, and learning resources through different teaching links. The author creates a mobile teaching environment by integrating the functions of information acquisition, resource sharing, multilevel interaction, and autonomous learning and exploration. Pre-class, classroom, and post-class teachings are effectively combined. The digital surveying teaching system based on the WeChat official account admin platform is shown in Fig. 1. The teaching system consists of three modules: the pre-class module, the classroom module, and the post-class module.

A. Pre-class module. The pre-class module focuses on publishing digital mapping teaching resources and learning objectives to enable students to learn about them through their smartphones or other mobile devices in a targeted manner. If the students have any questions, then they can discuss them with the teacher through the platform. The WeChat teaching groups built for this study are shown in Fig. 2. Fig. 2 (a) shows the Experiment and Practice WeChat group. Fig. 2 (b) illustrates the information publishing process before the class. Fig. 2 (c) presents the feedback of the students regarding the knowledge points that they are interested in.

B. Classroom module. During the classroom teaching process, teachers should spend most of their time helping students with autonomous learning after interpreting relevant knowledge points. In particular, a teacher should discuss knowledge points that the students have not yet understood through classroom teaching and should help address their uncertainties. 
C. Post-class module. This module is an important link of digital mapping teaching on the WeChat official account admin platform. It is integrated with several major functional modules, including private chat, WeChat group, moments, and functional plug-ins.

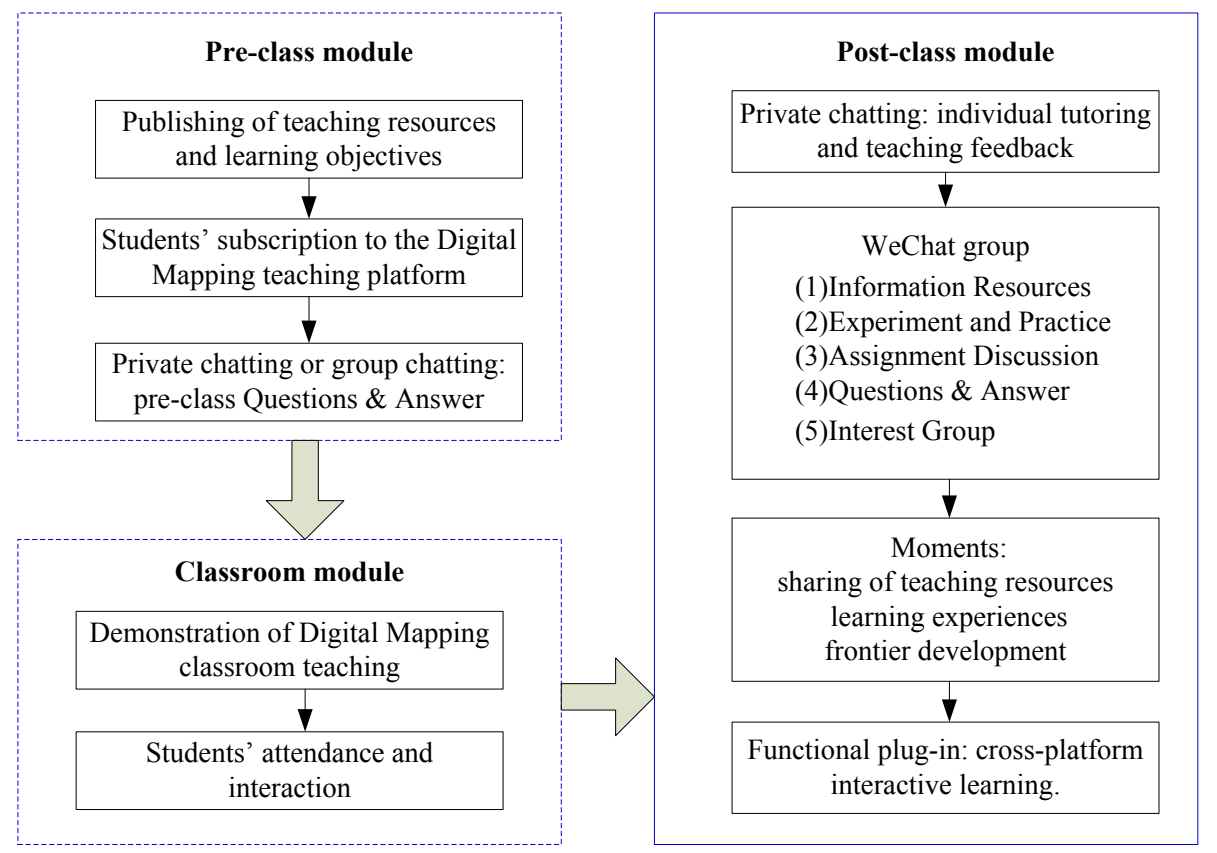

Fig. 1. Digital mapping teaching system based on the WeChat official account admin platform

The private chat module offers one-on-one interaction between a teacher and a student or between two students for individual guidance, question and answer (Q\&A), discussion, information sharing, and teaching feedback. The WeChat group module provides multi-person interaction either within a group or across different groups with various functions. All the students and teachers may join these groups.

Five groups are built for this study: Information Resources, Experiment and Practice, Assignment Discussion, Q\&A, and Interest groups. The teacher is a member of all the aforementioned groups to learn about the discussions of the students and to provide immediate guidance (Fig. 3). The moments module is mainly for one-to-many interaction. The teacher or students can share their teaching resources and learning experiences in the form of texts, images, and links. They can recommend frontier development information, videos of lectures by expert, and academic papers, among others. The functional plug-in module mainly serves to increase interaction efficiency and realize cross-platform interaction. The teacher and students can directly receive and send messages from QQ, browse and publish messages on Weibo, and receive and send emails through QQ mail services. 

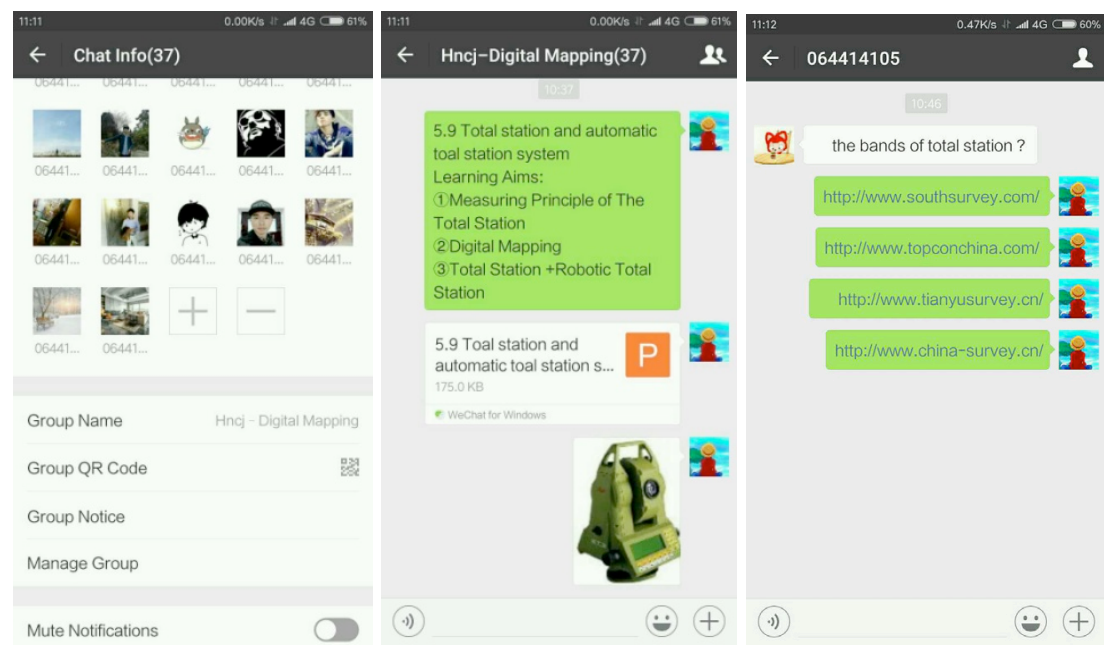

$\begin{array}{llll}\text { a) Digital mapping group } & \text { b) Publishing of teaching tasks } & \text { c) Feedback of students }\end{array}$

Fig. 2. Demonstration of pre-class module

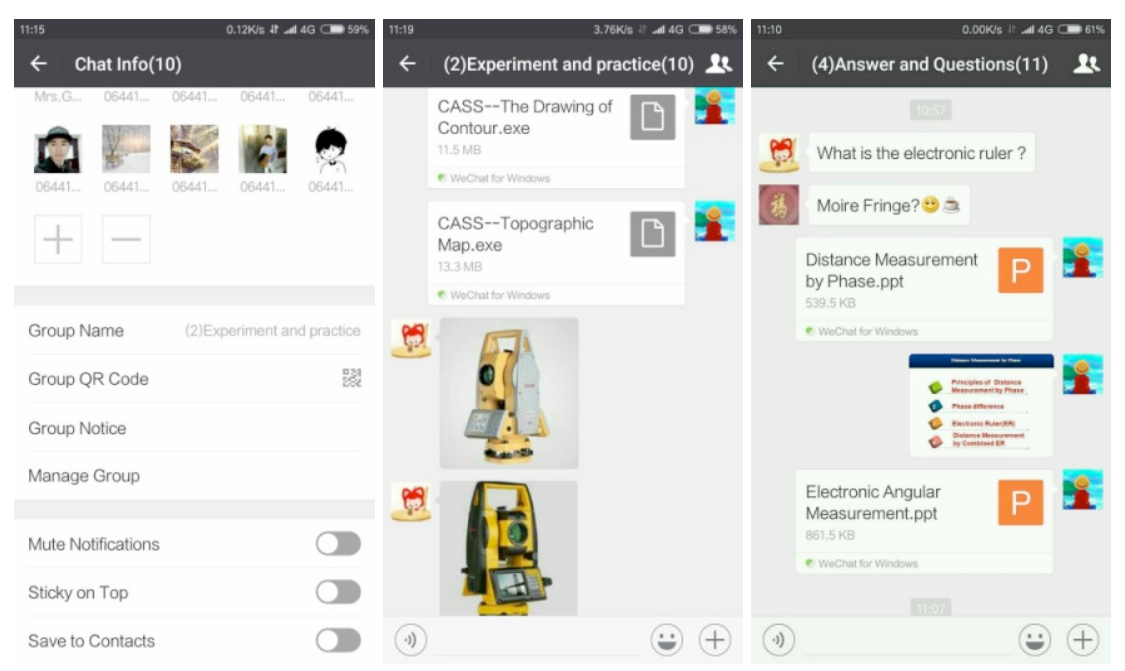

Fig. 3. Demonstration of post-class module

\subsection{Executive control of WeChat-based teaching}

Emphasizing the learning nature of the WeChat-based teaching platform: The launch of the digital mapping WeChat-based teaching platform creates an environment conducive to autonomous learning for students. However, some students may be involved in activities irrelevant to learning while using the WeChat platform. These activities, which include playing games, reading news, or chatting about personal affairs, will impair the quality of the WeChat-based teaching platform. Therefore, the 
teacher should emphasize the learning nature of the platform. Moreover, all members of the groups should be students learning digital mapping in the same semester. The aforementioned efforts can optimize the environment of WeChat-based teaching.

Classroom teaching first, WeChat-based teaching second: Classroom teaching should take precedence over WeChat-based teaching due to the limits of the latter. However, WeChat-based teaching should be used to immediately update teaching topics in digital mapping. A balance should be established between classroom teaching and WeChat-based teaching to achieve favorable teaching effects.

\section{$4 \quad$ Analysis of the effects of digital mapping mobile teaching based on the WeChat official account admin platform}

To test the effects of digital mapping mobile teaching, the author applied the new teaching model to the digital teaching course in academic year 2015-2016.

\subsection{Respondents}

This study selects 86 students majoring in Surveying Engineering from two parallel classes in Hunan University of Urban Construction as respondents. Among the 86 students, 43 are from Class 0644141, which comprise the test group. The remaining 43 are from Class 0644142, which comprise the control group. The teacher, teaching content, schedule, and hours for the two classes are the same.

\subsection{Research method}

The new teaching model is implemented in the test group, whereas the control group follows the traditional teaching model.

\subsection{Evaluation method}

Research data are collected through a contrast experiment (final, practice, and skill examinations) and a questionnaire survey. After the experiment, the test group and the control group are compared horizontally.

During the second semester of academic year 2016-2017, a unified exam was conducted among the test group and the control group. The exam content focuses on basic theoretical knowledge of digital mapping. On the last day of practice week during the second semester, total station small step point collection skills were tested to evaluate the operational ability of the students. All the test results are processed and analyzed using Microsoft Excel.

The students in the test group take an anonymous questionnaire survey. The author informs the students that the survey aims to determine the effects of applying the new teaching model, and thus, they should carefully answer the questions listed in Table 1 based on their practical experiences. 
Table 1. Questionnaire survey

\begin{tabular}{|c|l|}
\hline Item & \multicolumn{1}{|c|}{ Questions } \\
\hline 1 & Do you think using the WeChat-based digital mapping mobile teaching platform is convenient? \\
\hline 2 & Do you pay attention to contents related to digital mapping sent by your teacher every day? \\
\hline 3 & When do you use the teaching platform? \\
\hline 4 & Do you think the digital mapping teaching content posted on the teaching platform is reasonable? \\
\hline 5 & Do you think students actively interact with one another on the platform? \\
\hline 6 & Do you think the teaching platform has increased your interest in learning? \\
\hline 7 & Do you think the teaching platform has improved your autonomous learning ability? \\
\hline 8 & $\begin{array}{l}\text { Do you think the teaching platform has improved your learning effects or has expanded the range of } \\
\text { your knowledge? }\end{array}$ \\
\hline 9 & Are you willing to share your learning experiences with your classmates on the teaching platform? \\
\hline 10 & Are you willing to share your learning resources with your classmates on the teaching platform? \\
\hline 11 & Has the teaching platform strengthened the cohesion of the learning group or the class? \\
\hline 12 & Do you think the model is generally feasible? \\
\hline 13 & $\begin{array}{l}\text { Are you willing to get involve in similar WeChat-aided teaching activities in other courses apart } \\
\text { from digital mapping? }\end{array}$ \\
\hline 14 & What do you think of the model? Do you have any suggestions for its improvement? \\
\hline
\end{tabular}

\subsection{Analysis of teaching effects}

The results of the final exam performance and the practical skill test of the test group and the control group are presented in Table 2.

Table 2. Comparison of the performances of the students in the two teaching models

\begin{tabular}{|l|c|c|c|}
\hline \multicolumn{1}{|c|}{ Class } & $\begin{array}{c}\text { Average scores and standard } \\
\text { deviation of the final exam }\end{array}$ & $\begin{array}{c}\text { Average scores and standard devia- } \\
\text { tion of the practical skill test }\end{array}$ & $\begin{array}{c}\text { Average time } \\
\text { taken }\end{array}$ \\
\hline Test group & $88.02+6.30$ & $85.47+6.80$ & $2 \mathrm{~min} 30 \mathrm{~s}$ \\
\hline Control group & $78.39+7.47$ & $82.78+8.20$ & $3 \mathrm{~min} 45 \mathrm{~s}$ \\
\hline
\end{tabular}

Table 2 shows that the average scores of the test group and the control group are 88.02 and 78.39 , respectively. The scores of the test group are evidently higher than those of the control group. Furthermore, the standard deviation of the test group and the control group is 6.03 and 7.47 , respectively. The gap among students in the control group is considerably wider than that among students in the test group. This result suggests that the test group exhibits greater improvement in terms of basic theoretical knowledge compared with the control group. The practical skill test shows that the time taken by students in the test group to complete the practical skill test is $1 \mathrm{~min}$ and $15 \mathrm{~s}$ shorter than that taken by students in the control group. This finding suggests that the practical skills of the students in the test group have also improved. In summary, the new teaching model has achieved satisfying teaching effects either in terms of basic theoretical knowledge or practical skills. In addition to the first questionnaire survey, a second questionnaire survey is conducted among students in the test group. The second survey focuses on three aspects: WeChat learning hours, attitude toward 
the applications of WeChat to teaching, and application effects of WeChat-based teaching. The statistical results are presented in Fig. 4 and Tables 3 and 4.

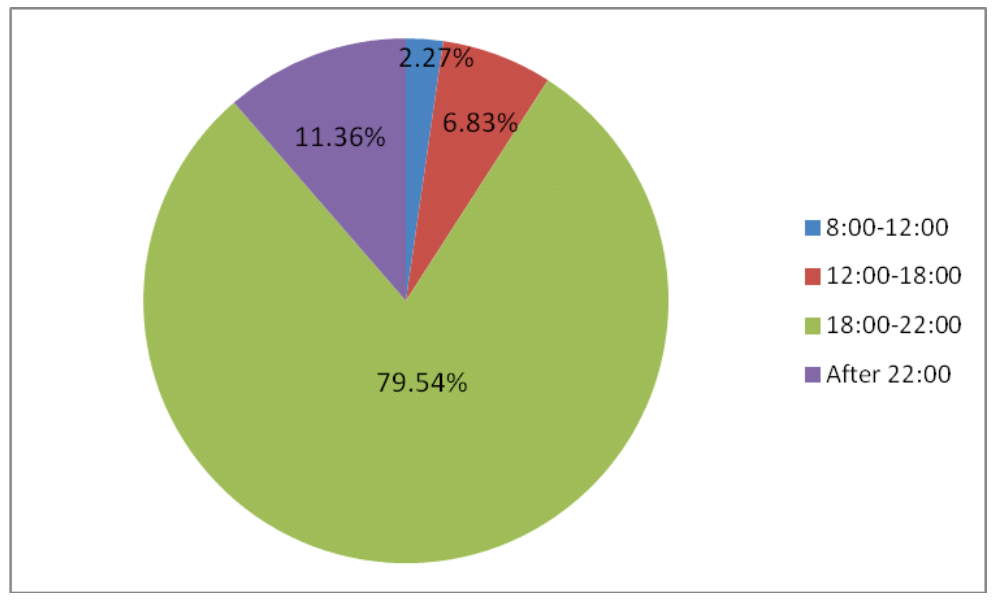

Fig. 4. Period of WeChat usage

As shown in Fig. 4, WeChat usage is concentrated in two periods: 18:00-22:00 and after 22:00. Only a few students can find time to use WeChat during daytime. Hence, the period of WeChat usage is closely associated with course arrangement and extracurricular activities. Students are busy during daytime, and they only have time to surf the Internet in the evening. However, the school will turn off the lights after 22:00 to compel the students to go to bed. After going to bed, the students are accustomed to playing on their mobile phones. Furthermore, most students are already worn-out by this time and will chat about things that are irrelevant to learning or merely check the moments posted by their friends. Therefore, the learning enthusiasm of the students has faded after 22:00. Teachers should fully utilize the period from 18:00 to 22:00 to publish course resources and important notices, as well as to communicate with learners online.

Table 3. Statistics on the attitude of students toward WeChat-based teaching

\begin{tabular}{|l|c|c|c|}
\hline \multicolumn{1}{|c|}{ Questions } & \multicolumn{2}{c|}{ Choices } \\
\cline { 2 - 4 } & Yes & Neutral & No \\
\hline $\begin{array}{l}\text { Do you think using the WeChat-based digital mapping mobile teaching plat- } \\
\text { form is convenient? }\end{array}$ & $93.02 \%$ & $6.98 \%$ & 0 \\
\hline $\begin{array}{l}\text { Do you pay attention to contents related to digital mapping sent by your } \\
\text { teacher every day? }\end{array}$ & $97.73 \%$ & $2.27 \%$ & 0 \\
\hline Do you think students actively interact with one another on the platform? & $97.73 \%$ & $2.27 \%$ & 0 \\
\hline $\begin{array}{l}\text { Are you willing to share your learning resources with your classmates on the } \\
\text { teaching platform? }\end{array}$ & $90.70 \%$ & $9.30 \%$ & 0 \\
\hline Do you think the model is generally feasible? & $97.67 \%$ & $2.33 \%$ & 0 \\
\hline $\begin{array}{l}\text { Are you willing to get involve in similar WeChat-aided teaching activities in } \\
\text { other courses apart from digital mapping? }\end{array}$ & $97.67 \%$ & $2.33 \%$ & 0 \\
\hline
\end{tabular}


As shown in Table 3, over $90 \%$ of the students think that using the WeChat-based digital mapping mobile teaching platform is convenient and they are willing to pay attention to the contents shared by their teachers regarding digital mapping. They also enjoy learning and sharing learning resources on the WeChat platform. Furthermore, $97.67 \%$ of students commend the new teaching model and are willing to learn other courses aside from digital mapping through this model.

Table 4. Statistics of WeChat-based teaching effects

\begin{tabular}{|l|c|c|c|c|}
\hline \multicolumn{1}{|c|}{ Questions } & \multicolumn{2}{c|}{ Choices } \\
\cline { 4 - 5 } & $\begin{array}{c}\text { Strongly } \\
\text { agree }\end{array}$ & Agree & Neutral & Disagree \\
\hline $\begin{array}{l}\text { Do you think the digital mapping teaching content posted on } \\
\text { the teaching platform is reasonable? }\end{array}$ & $83.72 \%$ & $11.63 \%$ & $4.65 \%$ & 0 \\
\hline $\begin{array}{l}\text { Do you think students actively interact with one another on the } \\
\text { platform? }\end{array}$ & $86.05 \%$ & $9.30 \%$ & $4.65 \%$ & 0 \\
\hline $\begin{array}{l}\text { Do you think the teaching platform has increased your interest } \\
\text { in learning? }\end{array}$ & $86.05 \%$ & $9.30 \%$ & $4.65 \%$ & 0 \\
\hline $\begin{array}{l}\text { Do you think the teaching platform has improved your auton- } \\
\text { omous learning ability? }\end{array}$ & $81.40 \%$ & $9.30 \%$ & $9.30 \%$ & 0 \\
\hline $\begin{array}{l}\text { Do you think the teaching platform has improved your learn- } \\
\text { ing effects or has expanded the range of your knowledge? }\end{array}$ & $86.05 \%$ & $11.63 \%$ & $2.32 \%$ & 0 \\
\hline $\begin{array}{l}\text { Has the teaching platform strengthened the cohesion of the } \\
\text { learning group or the class? }\end{array}$ & $81.39 \%$ & $6.98 \%$ & $11.63 \%$ & 0 \\
\hline
\end{tabular}

As shown in Table 4, 83.72\% of the students strongly agree that the digital mapping teaching contents sent by their teachers is reasonable, and $11.63 \%$ agree. These results show that the learning resources sent by the teachers are highly targeted. Furthermore, over $86 \%$ of the students strongly agree that students actively interact with one another on the platform, and nearly $10 \%$ agree. In addition, the statistics show that the new teaching model has improved the interest of students in learning and has expanded their range of knowledge. This result can be mainly attributed to the interesting learning resources and frontier development information on surveying subjects posted by the teachers before the class. Lastly, over $81 \%$ of students strongly agree that the platform has improved their learning effects and has strengthened the cohesion of their class.

\section{Conclusions}

The traditional teaching model for digital mapping faces numerous problems, such as inadequate interaction, single teaching methods, and insignificant improvement of the autonomous learning ability of students, due to limits in classroom size and class hours. To address these problems, this study built a digital mapping mobile teaching platform based on WeChat and applied it to teaching practices for students majoring in Digital Mapping in Hunan University of Urban Construction. The following conclusions are drawn from this study. 
1. The new teaching model eliminates the limits of time and space. Students can learn and exchange knowledge with one another through the WeChat teaching platform at any time and place. Through the new teaching model, learning is transformed from a passive activity into an active activity, and the cohesion of the class is strengthened.

2. The new teaching model is a beneficial supplement to traditional digital mapping teaching. Before the class, students can be informed of the learning objectives through the WeChat platform, thereby allowing them to learn in a targeted manner. The interest in learning of the students and their autonomous learning ability are also enhanced significantly.

3. The new teaching model can undoubtedly widen the horizon of the students and enrich their professional knowledge through the posting of learning resources.

4. Teaching digital mapping based on the WeChat official account admin platform plays a positive role in improving the learning effects and operational ability of students.

Despite the aforementioned benefits, this study is merely a preliminary exploration of teaching digital mapping through the WeChat official account admin platform. Further research should be conducted to determine whether these findings are applicable to the development of other surveying engineering courses.

\section{References}

[1] Hua Xianghong, Xiang Dong, Zou Jingui and Zhao Lan,Discussion on the teaching reform of the digital topographic surveying based on geomatics skill competition, Experiment Science and Technology,2016, Vol. 14(3), pp. 69-71.

[2] Yang Leiduo,Zhou Hui,Research on course construciton and practice of project driven digital mapping technology in higher vocational education, Journal of Guangdong Communication Polytechnic,2016, Vol. 15(4), pp. 86-90.

[3] Zhang Haining,Sun Jiuyun,Liu Chao and Pang Youzhi, Research on teaching and experiment reform of large scale digital topographic mapping,GNSS World of China,2015, Vol. 40(3), pp. 98-100.

[4] Cheng Gang,Ge Xiaosan,Yu Haiyang and Lu Xiaoping,Practice Teaching of Principles and Methods of Digital Mapping,Geospatial Information,2011, Vol. 9(1), pp. 150-152.

[5] Fan Wenxiang,Ma Yan,Li Kai and Qiu Bingfa,A practical study in the flipped classroom based on wechat under environment of mobile learing,Opern Education Research,2015, Vol. 21(3), pp. 90-97.

[6] TM Miangah and A Nezarat, Mobile-Assisted Language Learning, International Journal of Distributed and Parallel Systems, 2012, Vol. 3(1), pp. 309-319. https://doi.org/10.5121/ ijdps.2012.3126

[7] Wang Ping, Analysis of support functions and design principles of mobile learning based on wechat,Journal of Distance Education ,2013, Vol. 1(6), pp. 34-41.

[8] Liu Hui, Study on mobile blended learning model SECOND based on WeChat public platform.Modern Electronics Technique, 2017, Vol. 40(3), pp. 34-37.

[9] Xie Wei, A probe into the construction of product design resource course based on wechat platform. Theory and Practice of Education, 2016, Vol. 36(6), pp. 40-42. 
[10] Chi Zong zheng,Hou Gang,Lai Xiaochen and Ren Zhilei, Construction of a mobile assistant teaching platform based on new technology,Research and Exploration in Laboratory,2016, Vol. 35(5), pp. 166-169.

\section{$7 \quad$ Authors}

Caiyun Gao is a lecturer in School of Geomatics \& Urban Information, Henan University of Urban Construction, Pingdingshan 467036, China (gaocaiyungao@163.com).

Jingyan Wang is a lecturer in Department of Communication Engineering of Shijiazhuang Information Engineering Vocational Collage, Shijiazhuang, 050000, China (44495564@qq.com).

Article submitted 15 May 2017. Published as resubmitted by the authors 26 June 2017. 